\title{
Re-evaluation of the Conceptualisation of Super Levees by Focusing on the Availability of Open Space as an Evacuation Area along the Arakawa River
}

\author{
Nurul Ashikin Binti Mabahwi ${ }^{1}$, Hitoshi Nakamura ${ }^{2}$ \\ ${ }^{1}$ Graduate School of Engineering and Science, 2 Department of Planning, Architecture and Environment Systems, \\ Shibaura Institute of Technology, Saitama 216-0007, Japan \\ na18102@shibaura-it.ac.jp, nakamu-h@shibaura-it.ac.jp \\ Tel: +81 8059782012
}

\begin{abstract}
The objective of this study is to re-evaluate the conceptualisation of super levees by focussing on the availability of open spaces as evacuation areas along the Arakawa River. By using land use analysis, occupation analysis and cross-section, this study found that open spaces on super levees able to accommodate a large number of evacuees. This proves that the development of super levees is undeniably ready to provide sizeable safe upland evacuation area for nearby residents. This study also implies that the future development of super levee should include more open space by the development of a public park on the site.
\end{abstract}

Keywords: super levee; open space; flood; evacuation

eISSN: 2398-4287 @ 2019. The Authors. Published for AMER ABRA cE-Bs by e-International Publishing House, Ltd., UK. This is an open access article under the CC BYNC-ND license (http://creativecommons.org/licenses/by-nc-nd/4.0/). Peer-review under responsibility of AMER (Association of Malaysian Environment-Behaviour Researchers), ABRA (Association of Behavioural Researchers on Asians) and cE-Bs (Centre for Environment-Behaviour Studies), Faculty of Architecture, Planning \& Surveying, Universiti Teknologi MARA, Malaysia.

DOI: https://doi.org/10.21834/e-bpj.v4i11.1757

\subsection{Introduction}

The Eastern Lowland Districts of Tokyo face the risk of an urban flood disaster because the land area within the eastern Tokyo is roughly less than Arakawa Pail (A.P.) +5.1 metre. Since lowland is prone to flooding, in the year 1987, the River Council came up with a solution to protect the lower 58.2 kilometres of the river with high standard levee (super levees), (McKean, 2013). The River Council of Japan in a report entitled 'Recommendations on Policies for Protection from Extreme Floods' proposed a policy for protection from extreme floods to protect specific urban areas (Arakawa Karyu River Office, 2007). These urban areas comprised of a concentration of significant property and business functions such as Tokyo. The policy is applicable for extreme floods, which exceed the design levels of the regular flood protection measures (Takahasi and Unitto, 2004 in Stalenberg and Kikumori, 2008). This specific policy includes super levees projects. The high standard levee improvement project (super levees project) started along six large rivers in Tokyo and Osaka, for example, Tonegawa, Edogawa, Arakawa, Tamagawa, Yodogawa and Yamatogawa (Nakamura, 2016).

Prior 1996 to 2010 super levees project was conducted in approximately 13 districts, while from the year 2011 onwards about 4 to 7 districts. The improvement of the super levees as of March 2017 was about $120 \mathrm{~km}$. Approximately $14 \mathrm{~km}$ (around 12\%) of the basic cross-section of the high standard levee. The section where the form is secured is about $3.3 \mathrm{~km}$ (about 2.8\%), MLIT (2017a). The super levees maintenance projects conducted along Edogawa River, Arakawa River, Tamagawa River, Yodogawa River and Yamato River (MLIT, 2017a). For Arakawa River, there are 14 completed super levees projects at Shinsuna, Komatsugawa, Hirai, Hirai 7-chome, Senju, Odai, Odai 1-chome, Miyagi, Shinden, Shikahama, Kawaguchi, Kita-Akabane, Funado and Toda Koen.

Since the low-lying area is vulnerable to disaster, the importance to thoroughly examine evacuation of these areas are much needed. The Cabinet Office emphasised the evacuation methods described in the current hazard map of each municipality in a low-lying area will not be useful in the case of delay in evacuation caused by public transportation congestion, or if the number of evacuees exceeds 
the capacity of each designated evacuation area. Also stated it is necessary to examine other evacuation methods, such as temporarily evacuating evacuees to the upper floor of a school building or an upland area created by a large-scale high-standard levee in the neighbourhood as temporary evacuation shelter (Nakamura, 2016).

The previous scholar found that, if Arakawa River in Shinden district (super levee area) breached, people in an inundated area could evacuate to safe places in the neighbourhood on the condition that an appropriate evacuation system is established (Nakamura, 2016). The study found that the number of estimated potential evacuees $(11,280)$ at night exceeds the number of estimated night time evacuees $(3,187)$, and the number of estimated potential evacuees $(11,610)$ in the daytime exceeds the number of estimated daytime evacuees $(2,148)$. Besides, the number of potential evacuees who can evacuate to safe places within an inundated area is only 2,925 at night and 3,256 in the daytime. Which means neighbourhood evacuation for each evacuee will be difficult unless upland areas created through such means as super levees projects. Otherwise speaking, super levee has contributed to the creation of a large scale neighbourhood evacuation area in Shinden district (Nakamura, 2016).

Equally important, Allan and Bryant (2010) emphasised the need to plan and design open space for cities to contribute to urban and disaster resilience. Leon and March (2014) highlighted that open space for the evacuation area should have terrain quality. Because the height of super levees ensures higher places for evacuation in case of inundation, open spaces in super levees are considered as evacuation area with terrain quality.

In referring to the advertised concept of super levees, it stated that super levees developed with open space as an evacuation area. This study starts with the assumption that not all developed super levees equipped with open space as an evacuation area. Therefore, there is a need to re-evaluate the super levees' open space as an evacuation area.

\subsection{Objective of the study}

This study aimed to re-evaluate the conceptualisation of super levees by focusing on the availability of open spaces as evacuation areas. From the research, it is expected to determine the designated open space as an evacuation area in the super levees boundary and number of possible evacuees.

\subsection{Concept of the Super Levee}

High Standard Levee or super levee is a new type of levee that can withstand floods and earthquakes and built-in tandem with urban renovation projects (Arakawa-Karyu River Office, 2007). Super levees are extremely wide and capable of withstanding floodwaters. Even if the river overflows during significant flooding, the flood water spills out over gentle slopes, minimizing the damage to nearby urban areas and giving ample time to evacuate. Referring to Takeuchi (2002) in Luo et al., (2015), levee height is determined based on the maximum water level. Along Arakawa River, super levees area built approximately 10 metres high to protect Tokyo residents (Arakawa-Karyu River Office, 2017a).

The concepts of super levees development are, the wide must be 30 times more than its height (about $200 \mathrm{~m}$ to $300 \mathrm{~m}$ ). For example, the current height of levees should be 10 metres; therefore, the wide should be 300 metres with a gentler slope ration of 1:30. In addition, super levee has ground improvement and the ground is resistant to flooding and earthquake damage (Arakawa-Karyu River Office, 2017b)

Super levees must have easier access to the river; super levees embankments should link city streets to riverbanks with gently sloping hills (gentle slopes with a $3 \%$ gradient) for a more comfortable and enjoyable walk. Super levee too must be developed with emergency river road.

Other than that, once the ground level raised, the steep banks of the existing levee transformed into a flat open space that can put to a variety of uses (public roads, parks, evacuation areas). Super levees can also be evacuation sites when a disaster occurs because the height ensures a higher place for evacuation in case of inundation (Arakawa-Karyu River Office, 2007). Availability of these open spaces as evacuation areas gives residents greater peace of minds during floods and other disasters.

Wide-open views, meaning super levees open up skylines that were blocked by conventional levees, reuniting people with the river's water and greenery, creation of a pleasant living environment.

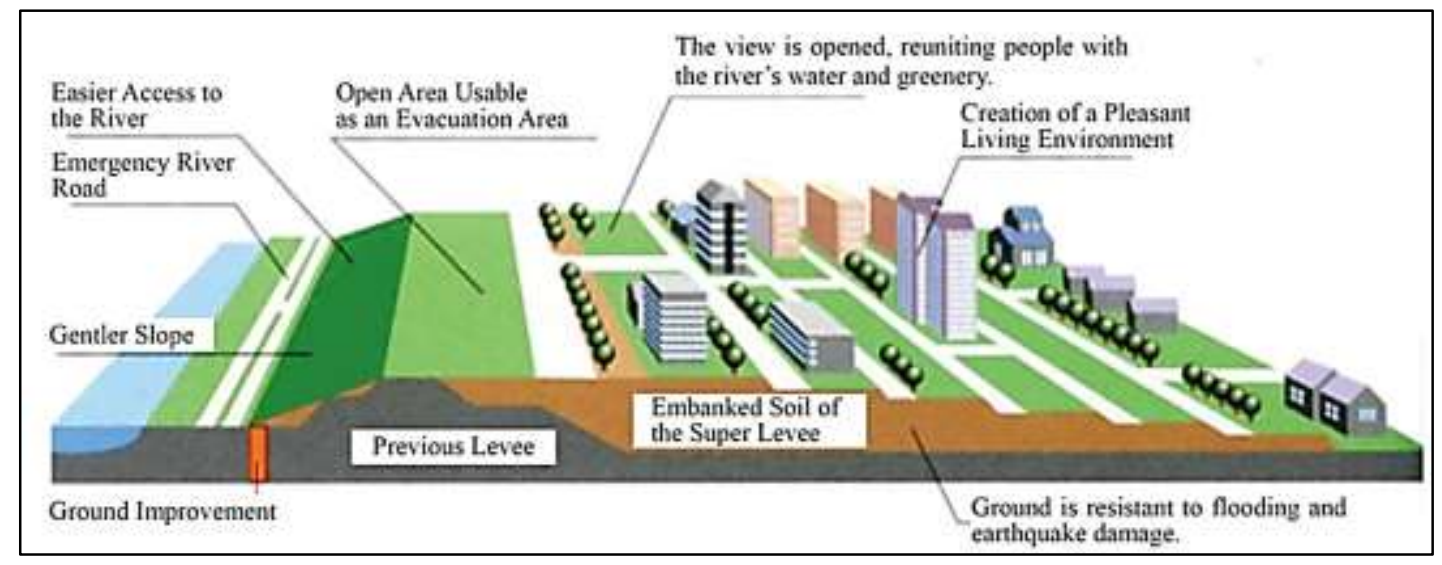

Fig. 1: The concept of super levee

(Source: Arakawa-Karyu River Office, 2007) 


\subsection{Summary effectiveness of super levee}

'Overflow', 'permeation' and 'liquefaction' are the problems that can be overcome by the super levees. When the flood is unexpectedly in large scale, there is a danger of levee breach due to overflow. However, super levee helps in preventing levee breach by allowing water to overflow gently on levee slope. There is also a danger of levee breach due to permeation when the flood is in large scale. But super levees able to prevent breach caused by destabilisation by making levees wider (MLIT, 2017b). Furthermore, urban area with soft ground might be damaged by liquefaction caused by a massive earthquake, and super levees able to prevent destructive damage by soil stabilisation. For the anti-overtopping function, the levee's slope at the backside of the river is gradual compared to the normal levee, the flow rate of the flowing water is reduced to improve the safety against the collapse of the levee by overtopping (MLIT, 2017b).

Super levee is not intended to be effective only when $120 \mathrm{~km}$ maintenance section completed, even if the basic cross-sectional shape not even completed, the levees still overflow, flood, permeation and liquefaction resistance (MLIT, 2017b).

Each super levee cannot be overtopped in the event of a large scale flood. So it can be utilised as a large scale upland evacuation area by creating open space. Even if some sections of the super levees are well developed, the remaining sections (without super levee) will be flooded. In this case, there is a possibility of failure from the conventional levee. Therefore, if there is a situation where the surrounding area is submerged super levee will function as a base of various activities such as rescue victims, transportation and emergency supply.

\subsection{Methodology}

\subsection{Study area}

Along Arakawa River, there are 14 completed super levee projects at Shinsuna, Komatsugawa, Hirai and Hirai 7-chome, Senju, Odai, Odai 1-chome, Miyagi, Shinden, Shikahama, Kawaguchi, Kita Akabane, Funado and Toda Koen and super levee in construction called Ukima (refer Fig. 2). However, due to the limitation of the study, the area chosen for this study only Komatsugawa, Hirai and Hirai 7 chome, Senju, Odai, Odai 1-chome, Miyagi, Shikahama, Kita-Akabane and Toda Koen.

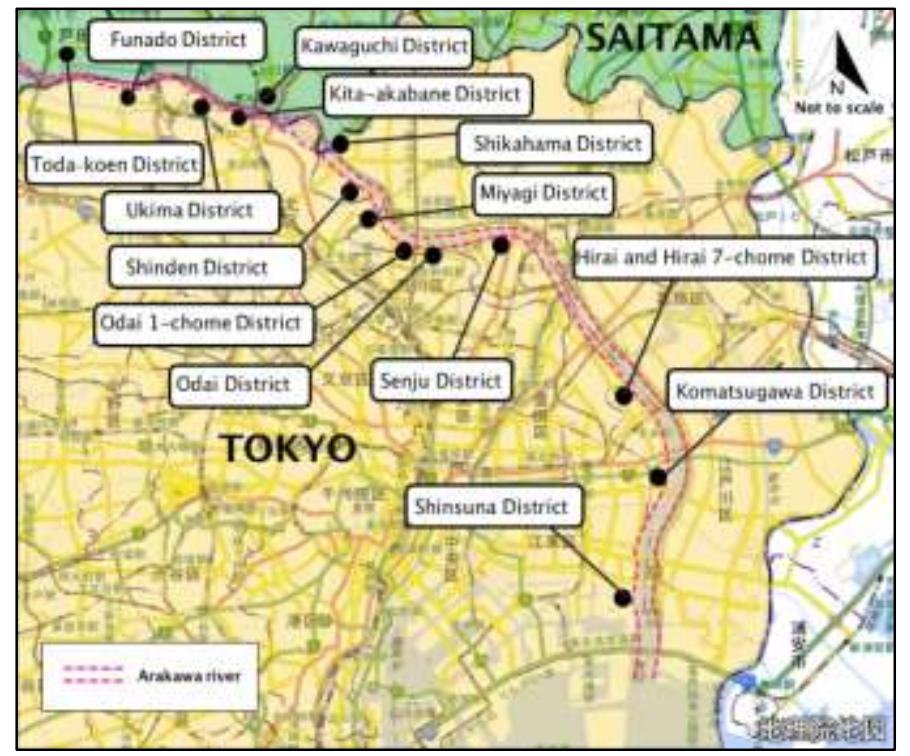

Fig. 2: Super levee along Arakawa River (Source: maps.gsi.go.jp, 2019)

\subsection{Data collection}

This study started by visiting all super levee's site to make an observation and determined its land use. Interview at Arakawa-Karyu River Office was conducted to gather necessary information and data. ArcGIS and Geospatial Information Authority Japan (GSI) application used in obtaining levee's height and ground-level data.

\subsection{The analysis procedure}

The analysis for this study started with elevation and cross-section analysis by using GSI. Next, this study made land use analysis by using GIS to determine the type of land use and possible open spaces as an evacuation area. Followed by assumption analysis to exclude distraction of trees, shrubs and built-up facilities on the open space. Last, an occupancy analysis to determine the number of evacuees. 


\subsection{Findings}

4.1 Elevation and width of the super levee

By using GIS and GSI, this study made cross-section analysis to determine the elevation of all super levee's district to ensure the height is according to the concept and suitable to be 'upland' evacuation area. Four areas built with levee's height less than 10 metres. Table 1 shows the size and height of each super levee's district:

Table 1. Height and wide of super levees

\begin{tabular}{lcr}
\hline Super levee districts & Horizontal distance (width metre) & Height (metre) \\
\hline Komatsugawa & 98 & 7.4 \\
Hirai & 40 & 6.5 \\
Hirai 7-chome & 130 & 6.5 \\
Senju & 100 & 10.1 \\
Odai & 40 & 6.9 \\
Odai 1-chome & 189 & 10.5 \\
Miyagi & 40 & 10.3 \\
Shikahama & 113 & 10.9 \\
Kita Akabane & 40 & 11.2 \\
Toda Koen & 147 & 10.3 \\
\hline
\end{tabular}

Note: Horizontal distance is based on the average width; Height is based on Tokyo Pail (T.P) and the average height of super levees

\subsection{Land use of super levee's district}

By using GIS, this study made land use analysis of super levee's site along Arakawa River. Land use of these super levee's site can be categorized as residential, public park, public facilities and mixed development. Komatsugawa consists of a large public park and mixeduse development. Hirai and Hirai 7-chome and Odai consist of residential areas. Senju and Kita Akabane correspond to public facilities. Miyagi, Shikahama and Toda Koen in the category of public park and Odai 1-chome classified as mixed-use development, refer to Fig. 3 until Fig. 11. The total area size for Komatsugawa is 23.3 hectares, 1.5 hectares for Hirai and Hirai 7 -chome, 1.0 hectare for Senju, 0.4 hectares for Odai, 6.8 hectares for Odai 1-chome, 1.2 hectares for Miyagi, 3.4 hectares for Shikahama, 2.0 hectares for Kita Akabane and 2.2 hectares for Toda Koen. Land use analysis helps in determining open space designated to be evacuation area. The results of land use analysis, as shown in Table 2.

Table 2. Land use of super levee's district

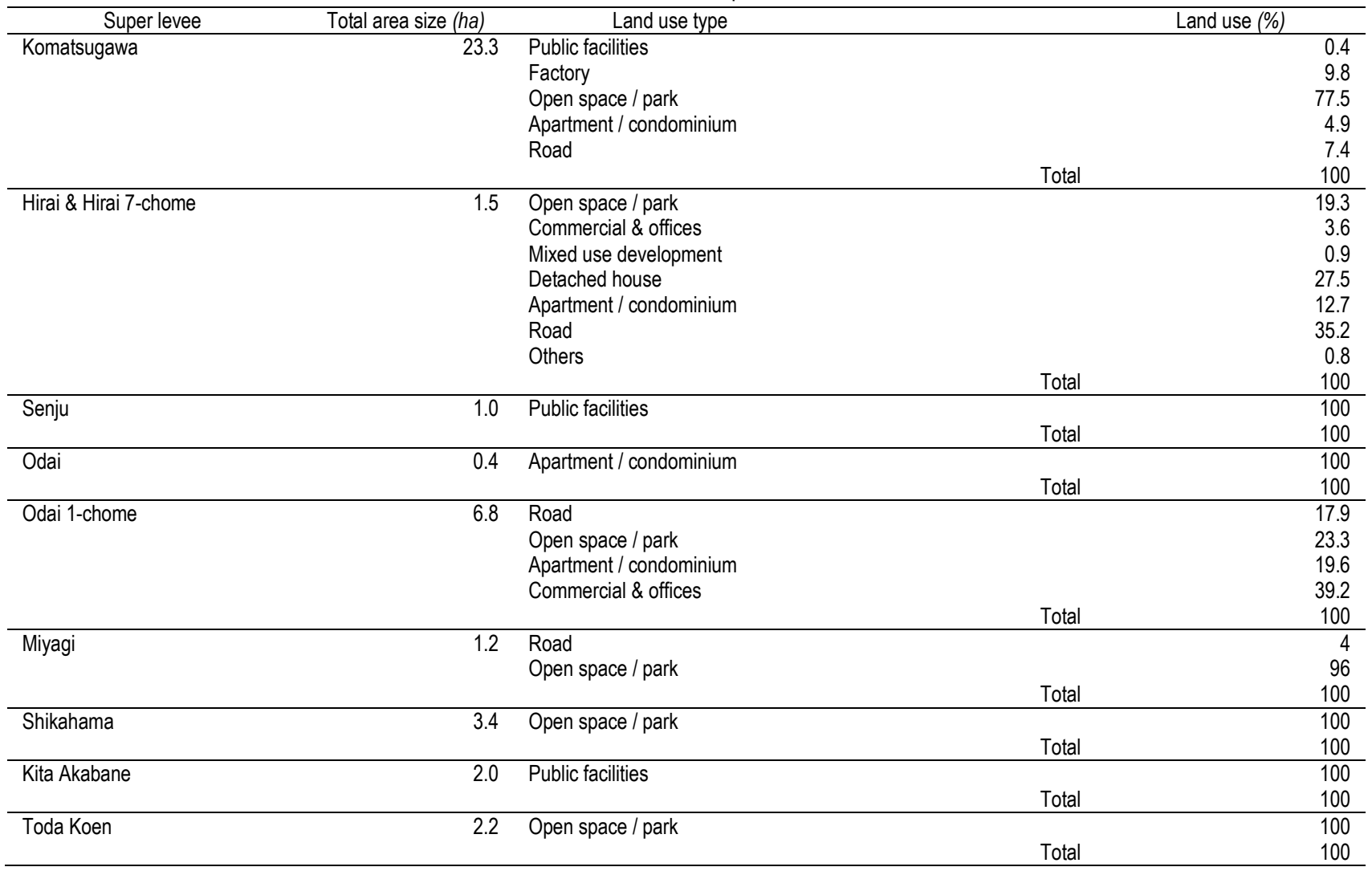




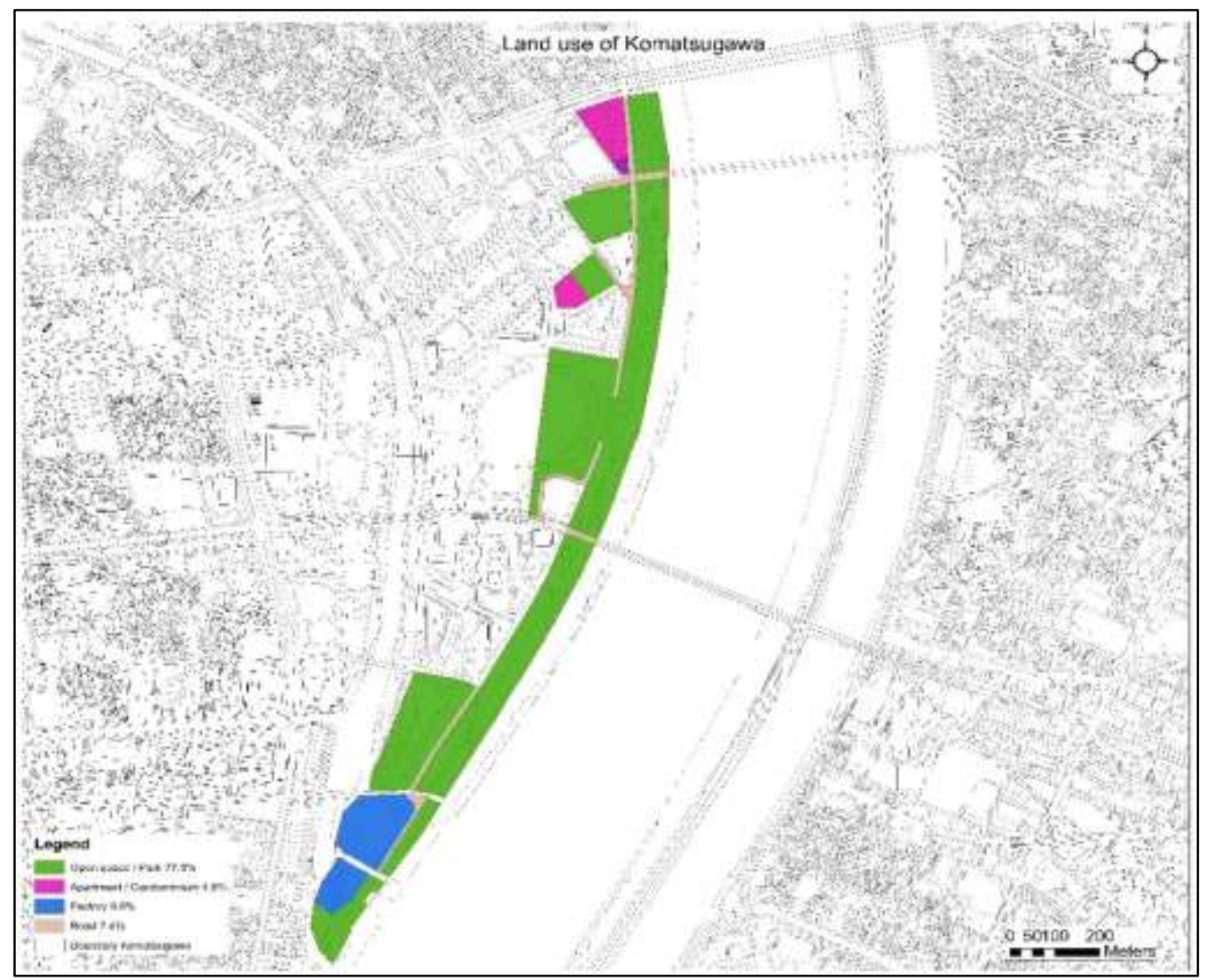

Fig. 3: Land use of Komatsugawa

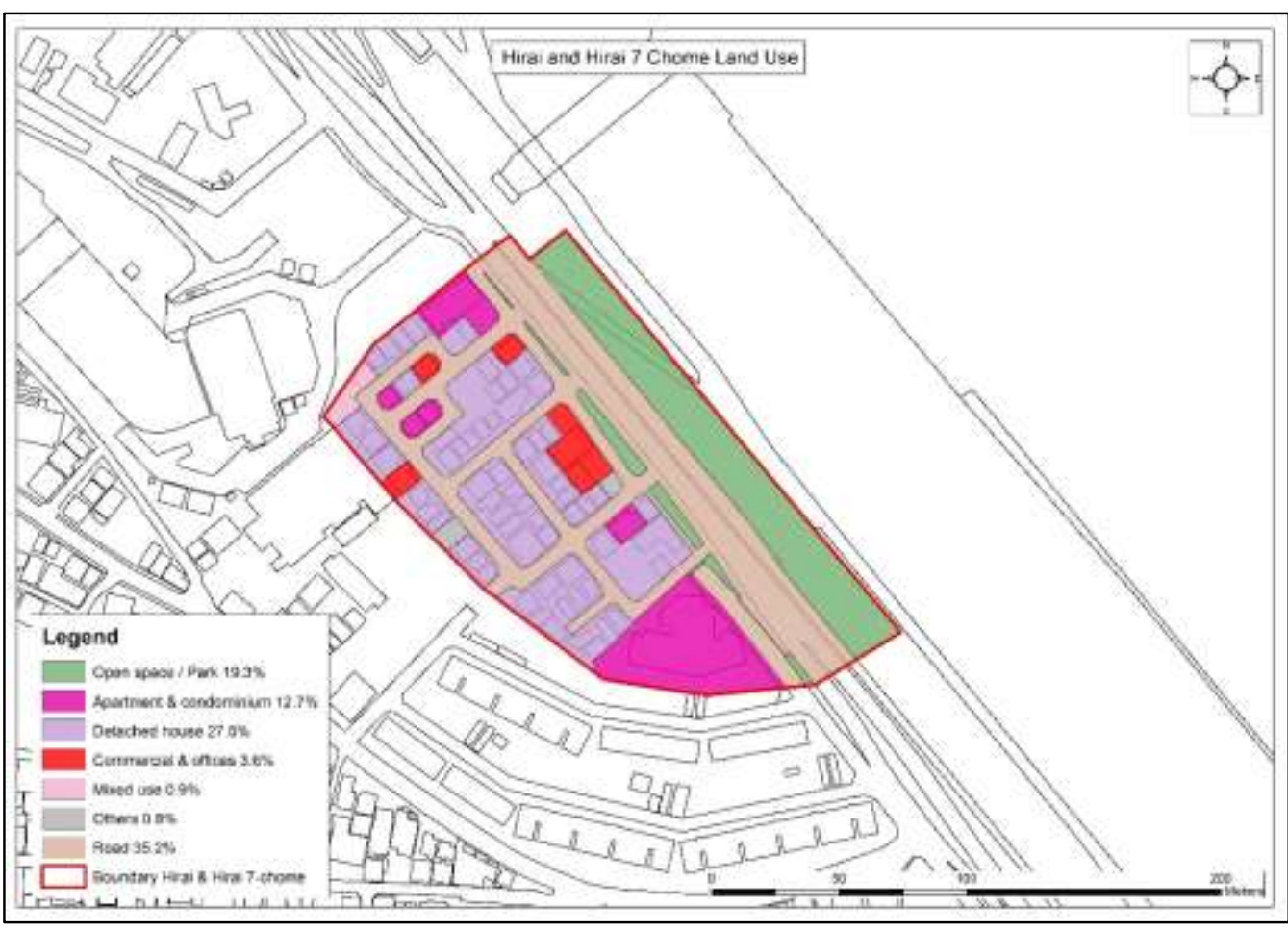

Fig. 4: Land use of Hirai and Hirai 7-chome 


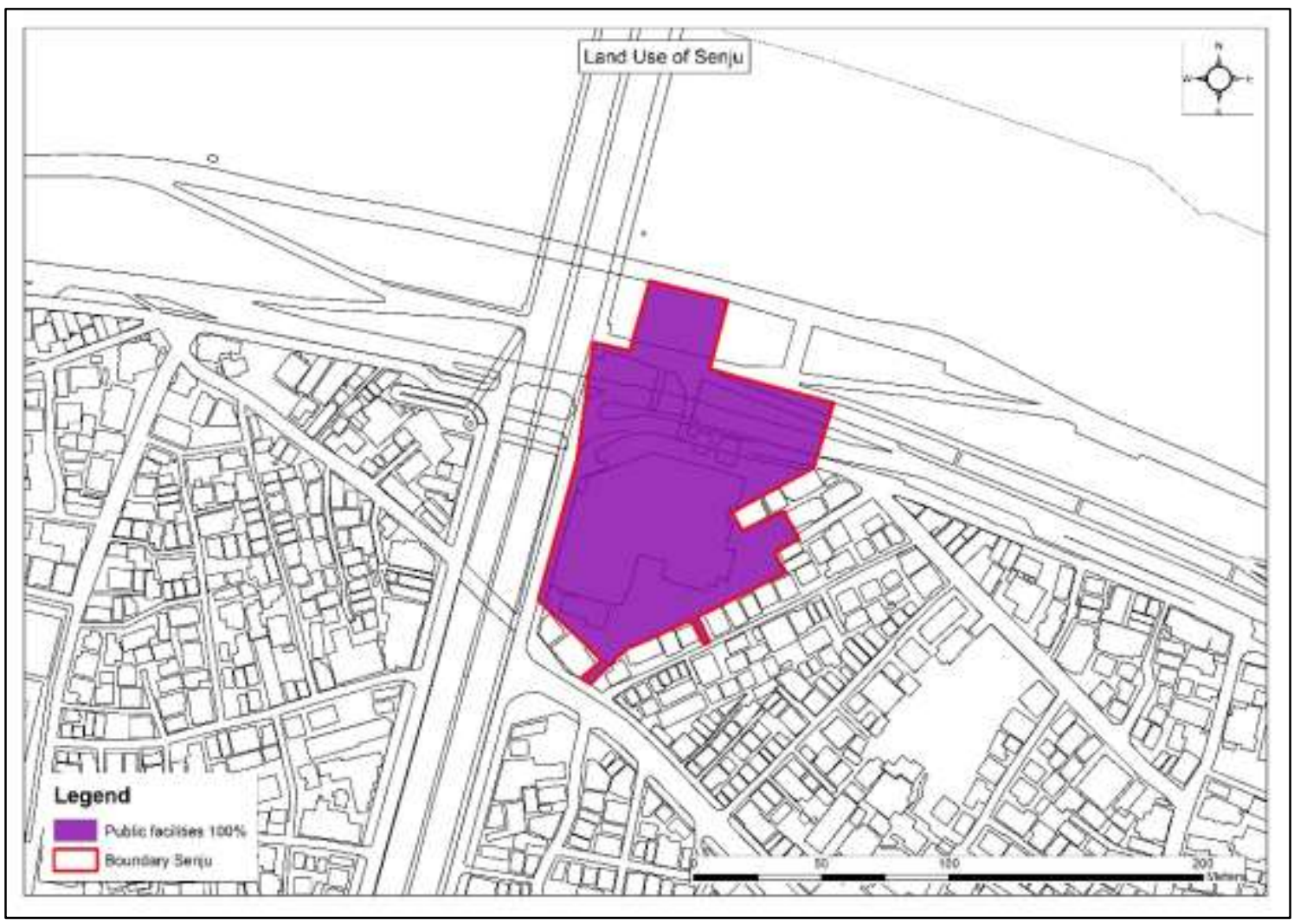

Fig. 5: Land use of Senju

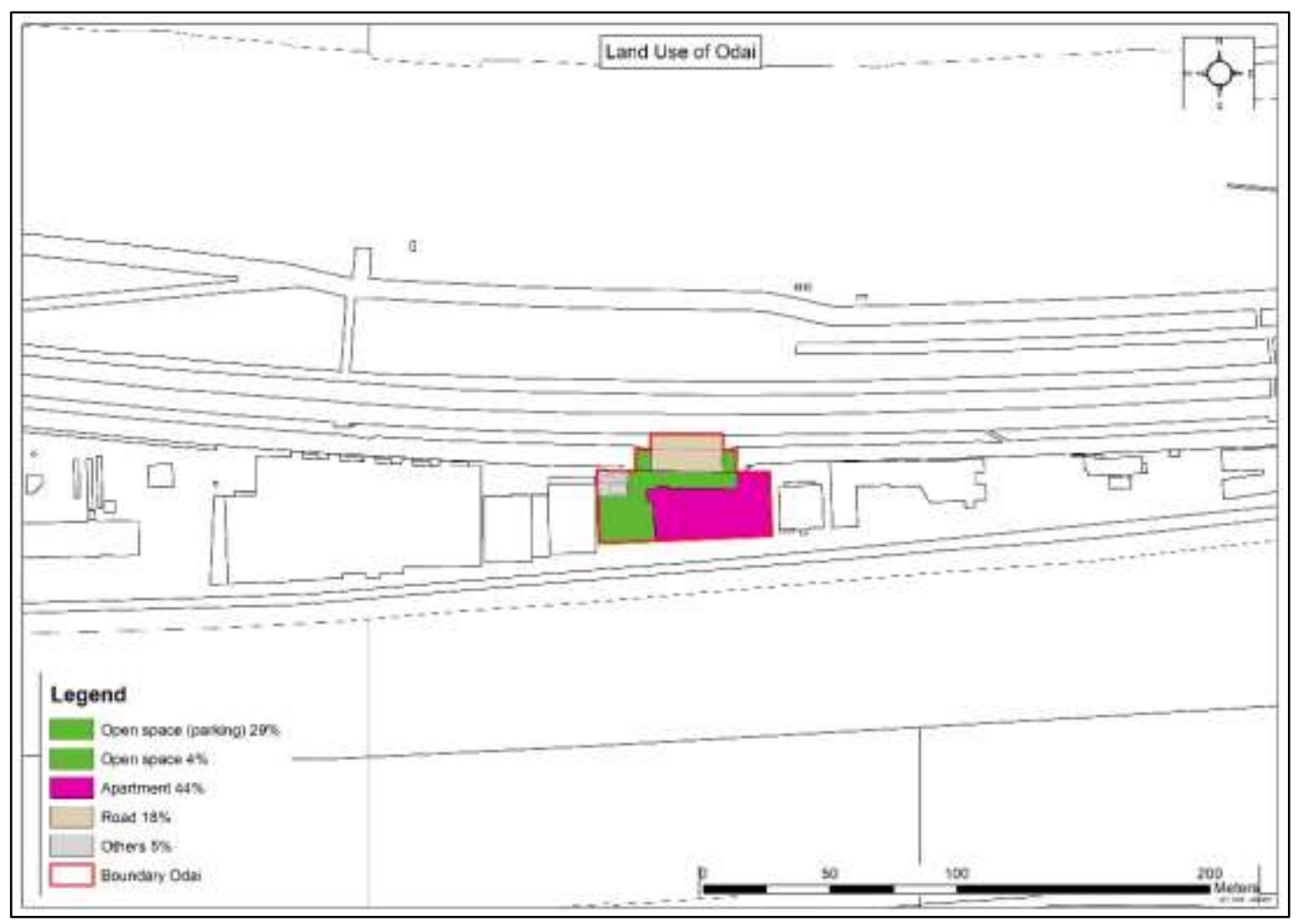

Fig. 6: Land use of Oda 


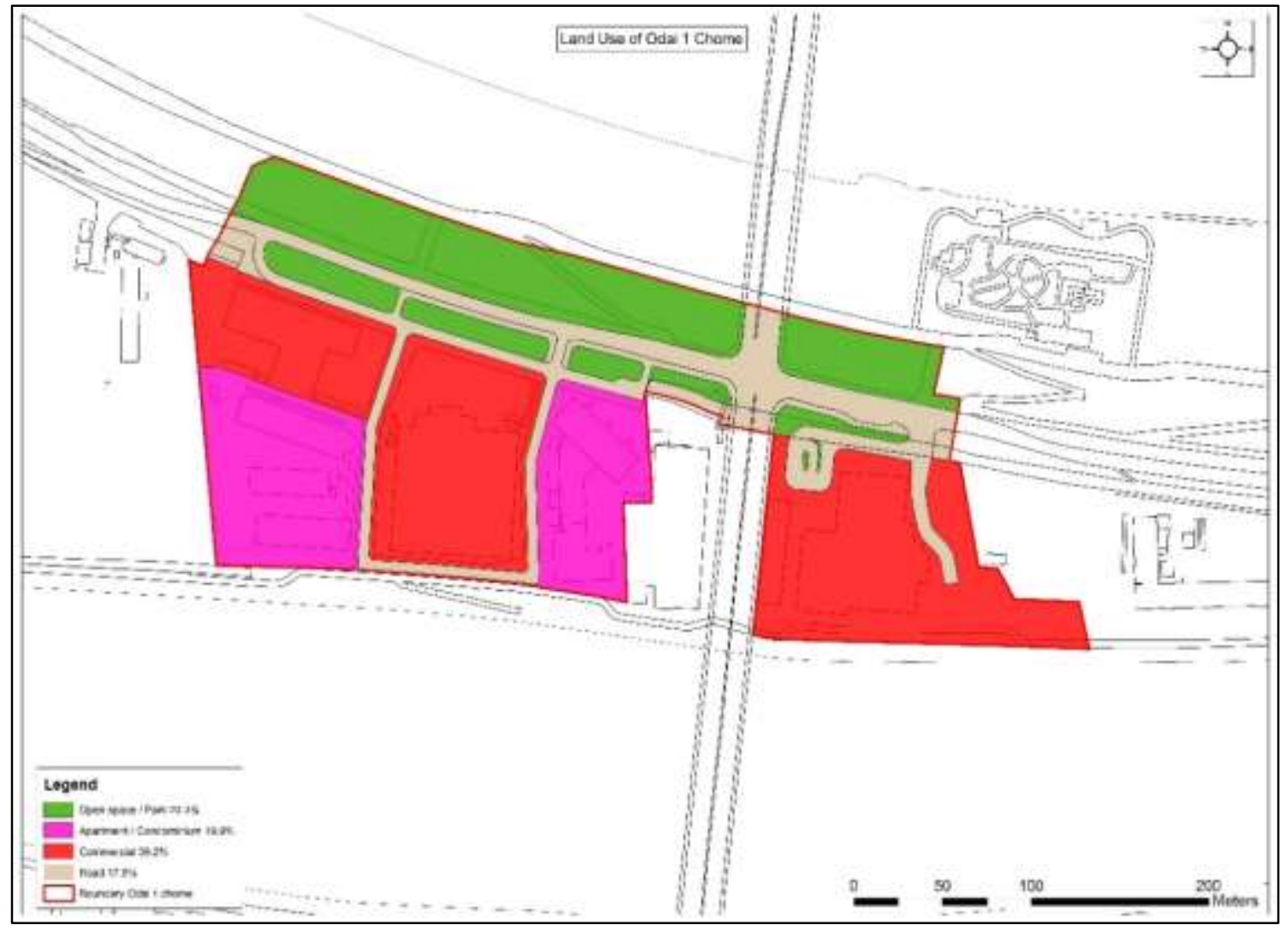

Fig. 7: Land use of Odai 1-chome

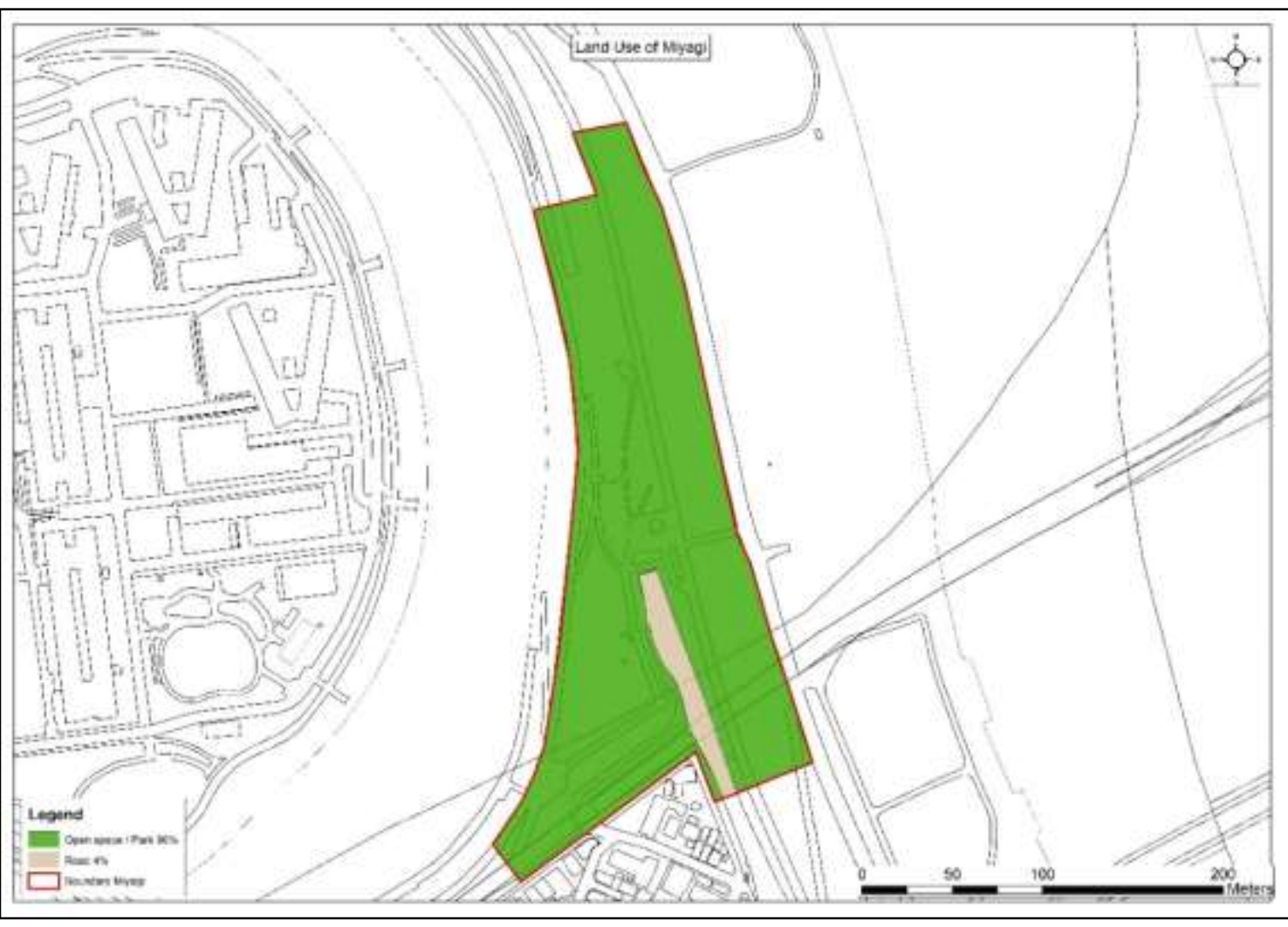

Fig. 8: Land use of Miyagi 


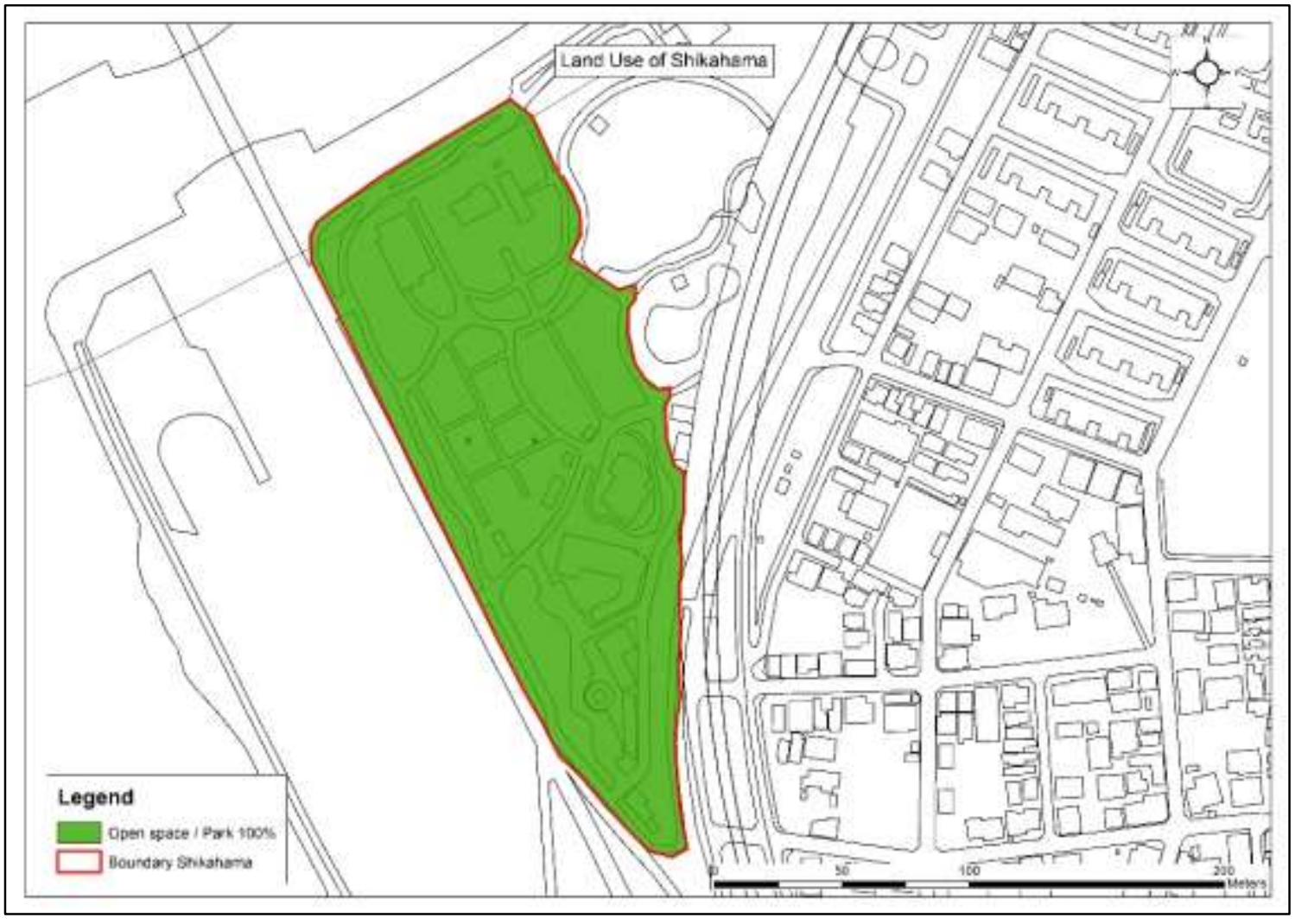

Fig. 9: Land use of Shikahama

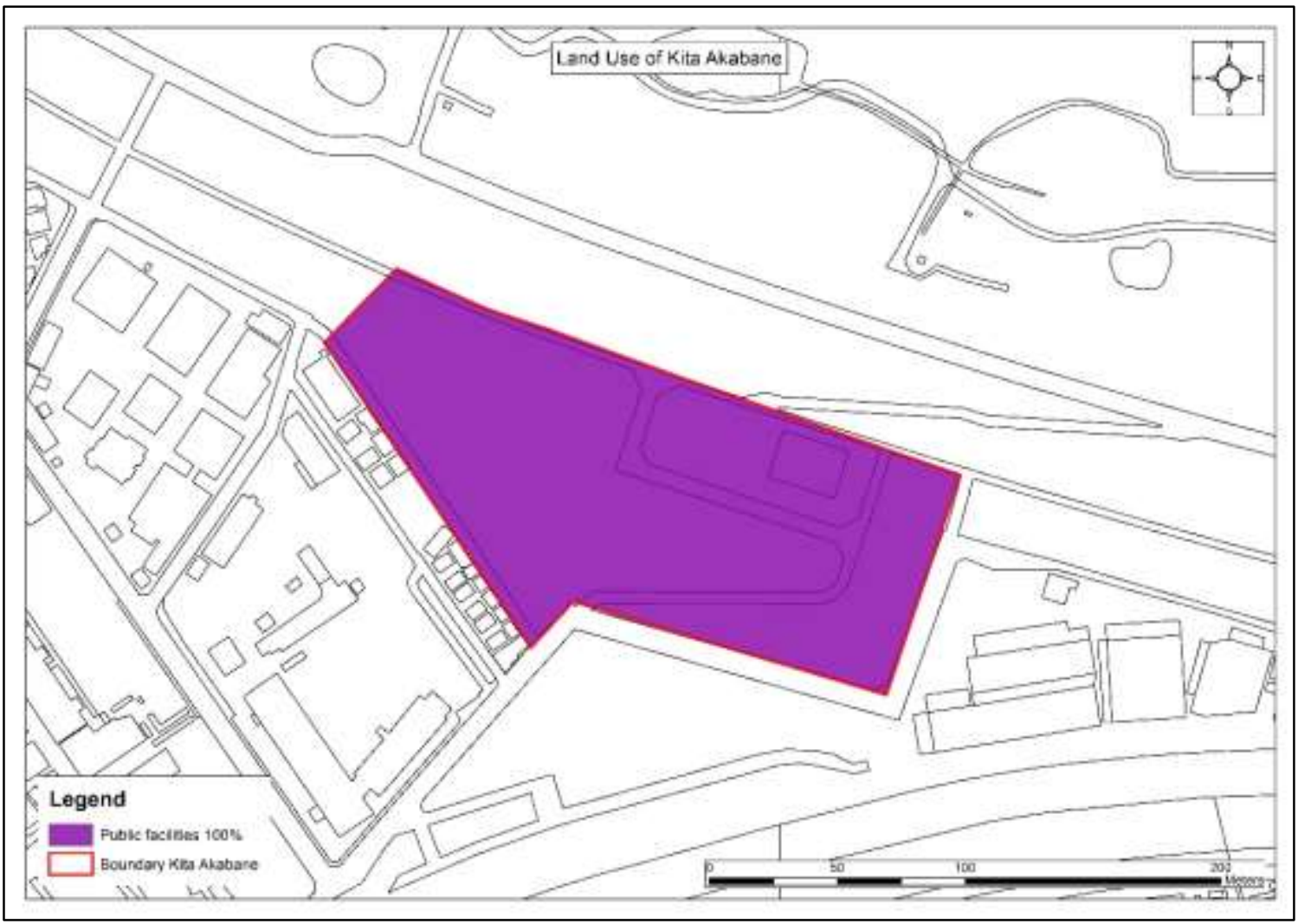

Fig. 10: Land use of Kita Akabane 


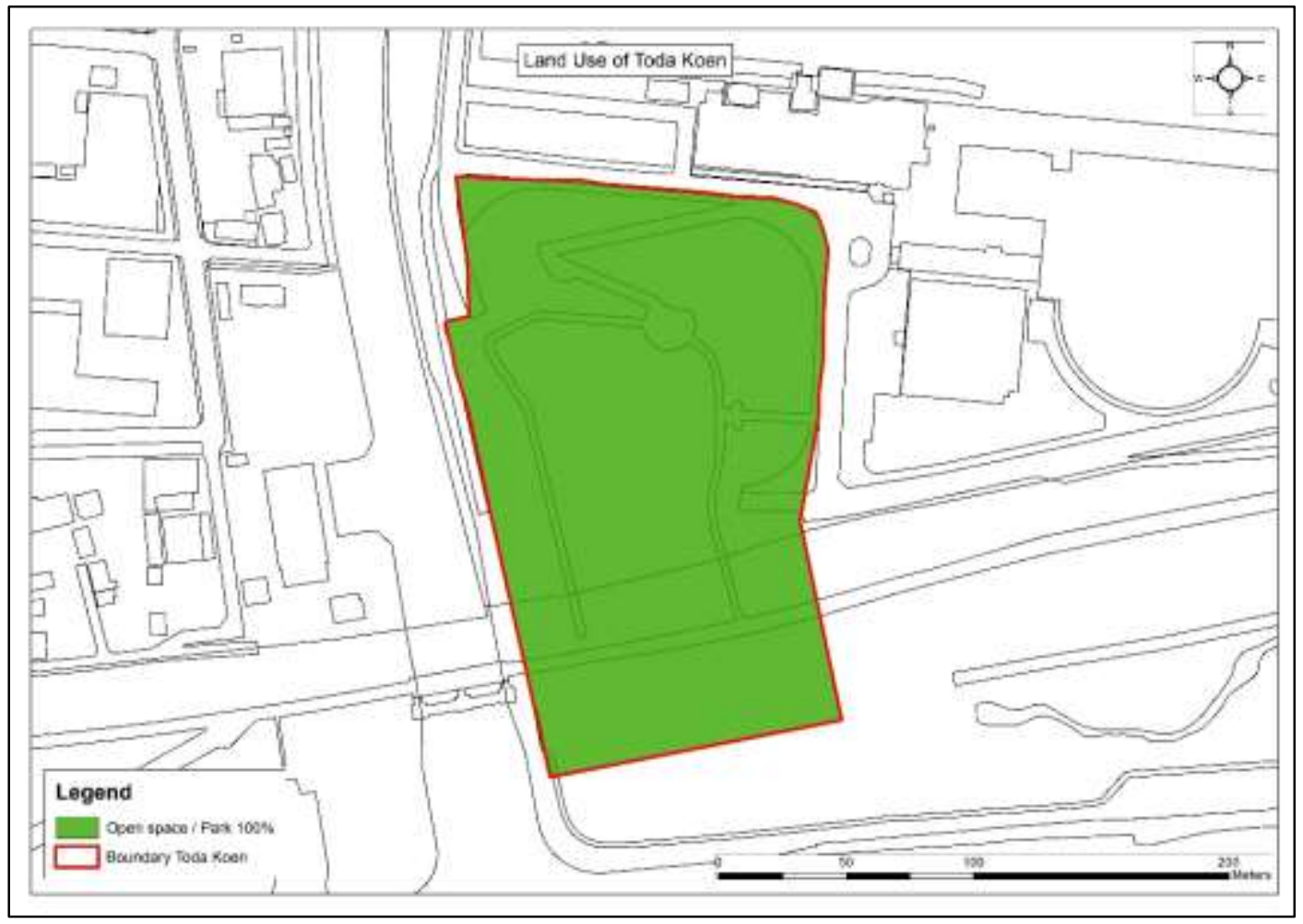

Fig. 11: Land use of Toda Koen

\subsection{Open spaces as an evacuation area}

This study analysed possible open spaces as an evacuation area in 10 super levee's districts along Arakawa River (Komatsugawa, Hirai and Hirai 7-chome, Senju, Odai, Odai 1-chome, Miyagi, Shikahama, Kita Akabane and Toda Koen). Open spaces as evacuation area were determined by observation during the site visit and each space was calculated and analysed by using GIS. This study used assumption analysis to exclude trees, shrubs, built up in open space such as benches, toilet, fountain and others. In minimising the possible error of assumption, calculation of the area was made by overlaying Landsat image with ArcMap. This technique is to ensure the deduction percentage of open area is reasonable. To calculate the number of possible evacuees, occupancy analysis was used with minimum space for each evacuee is $2 \mathrm{~m}^{2}$. Then, by using cross-section, the elevation of all evacuation area was determined to reconfirm the suitability as an upper land evacuation area (refer to Table 3).

Contrary to the super levee's concept to have open space as an evacuation area, this study found that Hirai and Hirai 7-chome, Senju, Odai, Odai 1-chome and Kita Akabane were not developed with open spaces. Therefore, there is a need to re-evaluate the concept of open space as evacuation space for these sites and take into consideration the use of parking lots, bicycle lots, sidewalks and residential roads.

$77.5 \%$ of land use in Komatsugawa are open space, mostly park and some vacant land. Out of $241,622 \mathrm{~m}^{2}$ open space, $80 \%$ can be an evacuation area with 96,649 possible evacuees. However, for Hirai and Hirai 7-chome, there is no designated open space to be an evacuation area. The only open space available located at the river bed of Arakawa River and close to auxiliary road (elevation approximately 6 metres). In this case, there is a possibility to use the narrow road along the residential area as a temporary evacuation area, because $40.2 \%$ of land use of the total area is residential with a narrow road. By deducting $17 \%$ of the auxiliary road, $6,397 \mathrm{~m}^{2}$ of the narrow road at the residential area of Hirai and Hirai 7-chome can be an evacuation area.

As for Senju, it is a public facility building with no designated open space. However, this building can be an 'upper building' evacuation area. But this study does not research on the use of building as an evacuation area. Therefore, by using land use analysis, we were able to detect small bicycle lot $\left(227 \mathrm{~m}^{2}\right)$ in front of the building that can be a small temporary evacuation space. With the assumption $20 \%\left(45 \mathrm{~m}^{2}\right)$ of the lot can be used as evacuation, 22 evacuees can seek temporary shelter at the area.

For Kita Akabane, despite not having open space, by observation study found that parking lots at the public facilities always empty. Therefore, about $4,100 \mathrm{~m}^{2}$ out of the parking area can be an evacuation space with 2,050 evacuees. The same case for Odai, there is no designated open space, and this study analysed its parking area to be temporary evacuation area. With the assumption $30 \%$ of the area can be used as evacuation, about 104 evacuees can take shelter at the $207 \mathrm{~m}^{2}$ open space in Odai.

Odai 1-chome consists of high rise residential area and commercial area. There is no designated open space or park in this area, but the sidewalks can be an evacuation area. With the assumption $80 \%$ of the sidewalk from the total area $\left(1,704 \mathrm{~m}^{2}\right)$ can be used as an evacuation area, 681 evacuees can evacuate to the sidewalk.

Land use of Miyagi is $96 \%$ public recreation park, which means $90 \%$ of the total area can be evacuation space and another $6 \%$ assumption of trees etc. Shikahama is an agriculture park, with regards to that, calculation of evacuation taken into consideration plantation of the area. $88 \%$ of the total area possible to be evacuation area. For Toda Koen, the land use is a park, and $52 \%$ of the site 
can be evacuation space with 7,220 evacuees. Unlike the other parks, there are no built-up facilities on Toda Koen. However, the remaining $48 \%$ of the area is unsuitable to be evacuation space because the average elevation is 5 metre, which is too low. Table 3 shows the availability of open space as an evacuation area and number of potential evacuees.

In short, if a disaster occurs, a sizeable number of evacuees able to evacuate to open space in Komatsugawa (96,649 evacuees), Miyagi $(7,200)$, Shikahama (44,000 evacuees) and Toda Koen (7,220 evacuees). The number of evacuees proves that super levee can create a large evacuation area on its open space.

However, results showed that the concept of 'open space as evacuation area' on super levees needs re-evaluation for Hirai and Hirai 7-chome, Senju, Odai, Odai 1-chome and Kita Akabane and consider the use of buildings or roads as evacuation space because these areas not developed with open space. Considering that we use parking lots, bicycle lots, sidewalks and roads as an evacuation area and 3,100 evacuees could evacuate to narrow roads in Hirai and Hirai 7-chome, 22 evacuees can evacuate to small bicycle lots in Senju, 681 evacuees to sidewalks in Odai 1-chome, 104 evacuees to parking lots in Odai and 2,050 evacuees to the parking lot in Kita Akabane.

Table 3. Possible evacuation spaces and evacuees on the super levee

\begin{tabular}{|c|c|c|c|c|c|}
\hline Super levee district & Open space $\left(m^{2}\right)$ & $\begin{array}{l}\text { Possible evacuation } \\
\text { space }\left(m^{2}\right)\end{array}$ & $\begin{array}{l}\text { Availability of evacuation } \\
\text { area on the total open } \\
\text { space (\%) }\end{array}$ & $\begin{array}{l}\text { Elevation of the } \\
\text { evacuation area }(m)\end{array}$ & $\begin{array}{l}\text { Number of possible } \\
\text { evacuees ( } 2 \mathrm{~m}^{2} / \text { person) }\end{array}$ \\
\hline Komatsugawa & 241622 & 193298 & 80 & 7.4 & 96649 \\
\hline Hirai \& Hirai 7-chome & 6397 & 6200 & 96 & 6.1 & 3100 \\
\hline Senju & 227 & 45 & 20 & 6.7 & 22 \\
\hline Odai & 691 & 207 & 30 & 6.8 & 104 \\
\hline Odai 1-chome & 1704 & 1363 & 80 & 6.2 & 681 \\
\hline Miyagi & 15360 & 14400 & 90 & 10 & 7200 \\
\hline Shikahama & 100000 & 88000 & 88 & 7.2 & 44000 \\
\hline Kita Akabane & 4209 & 4100 & 97 & 11.3 & 2050 \\
\hline Toda Koen & 28000 & 14440 & 52 & 11.5 & 7220 \\
\hline
\end{tabular}

Note: Open space is a public park, vacant land; Narrow road in Hirai and Hirai 7-chome is considered as evacuation area; parking lot in Kita Akabane is considered as an evacuation area

\subsection{Discussion}

This study focussed on open space as an evacuation area. The remaining concept for the development of super levees was not evaluated in this study because the availability of open space is the essential elements for evacuation, and disaster prevention is a crucial component of open space planning in Japan (Xu, 2013). Though super levees projects conducted in conjunction with urban redevelopment projects, out of 10 completed super levees, only 4 levees (Komatsugawa, Miyagi, Shikahama and Toda Koen) were developed with designated open space and can function as an evacuation area. To be specific, only levees developed as parks can accommodate evacuees on its open space with a significant percentage of space availability (refer to Table 3). Whereas, super levees developed as residential (Hirai and Hirai 7-chome, Odai), public facilities (Senju and Kita Akabane), and commercial (Odai 1-chome), were not equipped with open space as an evacuation area. This proves that the actual construction of super levees does not comply with the development concept of having open space as an evacuation area, and definitely in contrast with published promotions of super levees from the government. In another word, redevelopment projects conducted tandem with super levees do not consider evacuation in case of disaster as the planning element (by referring to the case of Hirai and Hirai 7-chome, Odai, Senju and Kita Akabane).

Therefore, there is a need to re-evaluate the concept of 'open space as an evacuation area' and use roads, commercial buildings, high rise apartments as temporary evacuation spaces instead. Besides, further research needs to consider the availability of high rise building floors (apartments and commercial buildings) for evacuation, especially for Senju, Odai and Odai 1-chome that currently have limited space for temporary evacuation.

\subsection{Conclusion}

In conclusion, super levees developed with open space undeniably able to provide sizeable safe upland evacuation area for nearby residents. However, the future study needs to re-evaluate the use of open space for evacuation and consider the use of high rise buildings and the road to overcoming scarce of evacuation areas for super levees developed without open space. This study hopes future development of super levee will include more open space as an evacuation area.

\section{Acknowledgements}

Our appreciation to Arakawa-Karyu River Office for the support.

\section{References}

Allan, P., \& Bryant. (2010). The critical role of open space in earthquake recovery: a case study. EN: Proceedings of the 2010 NZSEE Conference, 1-10.

Arakawa-Karyu River Office. (2007). Super levee guidebook. Tokyo, Japan: Author. 
Arakawa-Karyu River Office. (2017a). Briefing material - super levees. Tokyo, Japan: Author.

Arakawa-Karyu River Office. (2017b). Guide for the visit to the Arakawa River. Tokyo, Japan: Author.

Geospatial Information Authority of Japan (GSI). (2019). [map]. Retrieved from

http://maps.gsi.go.jp/\#5/36.104611/140.084556/\&base=std\&ls=std\&disp=1\&vs=c1j0h0k0l0u0t0z0r0s0m0f1

León, J., \& March, A. (2014). Urban morphology as a tool for supporting tsunami rapid resilience: A case study of Talcahuano, Chile. Habitat International, 43, 250262. doi:10.1016/j.habitatint.2014.04.006

Luo, P., He, B., Takara, K., Xiong, Y. E., Nover, D., Duan, W., \& Fukushi, K. (2015). Historical assessment of Chinese and Japanese flood management policies and implications for managing future floods. Environmental Science \& Policy, 48, 265-277. doi:10.1016/j.envsci.2014.12.015

McKean, C. A. (2013, December 4). Tokyo building enormous "super levees" to hold back its river. NextCity. Retrieved from https://nextcity.org/daily/entry/tokyo-isbuilding-enormous-super-levees-to-hold-back-its-river

Ministry of Land, Infrastructure, Transport and Tourism. (2017a). Current status of high standard levee. Retrieved from http://www.mlit.go.jp/river/shinngikai_blog/koukikaku_kentoukai/dai1kai/pdf/2-1_genjyo.pdf in Japanese

Ministry of Land, Infrastructure, Transport and Tourism (MLIT). (2017b). Towards the promotion of efficient maintenance of high standard levee. Retrieved from http://www.mlit.go.jp/river/shinngikai_blog/koukikaku_kentoukai/teigen.pdf in Japanese

Nakamura, H. (2016). Possibilities of neighborhood evacuation within a district in the event of a large-scale flood in a low-lying area: A case study of Shinden district in Tokyo. E3S Web of Conferences, 7, 19005. doi:10.1051/e3sconf/20160719005

Stalenberg, B., \& Kikumori, Y. (2009). Urban flood control on the rivers of Tokyo metropolitan. In Urban water in Japan (11th ed., pp. 119-141). Leiden, Netherlands: Taylor \& Francis. Edited by: Graaf \& Hooimeijer

Takahashi, Y., \& Uitto, J. I. (2004). Evolution of river management in Japan: from focus on economic benefits to a comprehensive view. Global Environmental Change, 14(8).

Takeuchi, K. (2002). Flood management in Japan-from rivers to basins. Water Int, 27, 20-26.

Tokyo Metropolitan Government. (2019). Lowland rivers projects in Tokyo. Retrieved from http://www.kensetsu.metro.tokyo.jp/english/jigyo/river/04.html

$\mathrm{Xu}, \mathrm{H}$. (2013). The evolution and characteristics of the green space system planning in Japan. Modern Landscape Architecture, 138-141. Retrieved from https://pdfs.semanticscholar.org/52a1/9dd5576d118c2acb8e0efa37e43682af0631.pdf 